\title{
THE REASONS FOR THE PLATINUM LOSSES IN THE METALLURGICAL PROCESSING OF COPPER-NICKEL ORES
}

\author{
${ }^{1}$ Alexei AMDUR, ${ }^{2}$ Sergei FEDOROV, ${ }^{1}$ Valery PAVLOV \\ ${ }^{1}$ Ural State Mining University, Yekaterinburg, Russian Federation, engineer-ektb@rambler.ru, \\ kat.shwab@yandex.ru \\ ${ }^{2}$ Institute of Metallurgy, Ural Branch of the Russian Academy of Sciences, Yekaterinburg, Russian \\ Federation, saf13d@mail.ru
}

https://doi.org/10.37904/metal.2020.3587

\begin{abstract}
The extraction of platinum from sulphide copper-nickel ores is a multi-stage process, which includes the melting of the prepared concentrate in electric ore smelting furnaces. In these furnaces, the melt is divided into matte and slag. Platinum is generally concentrated in matte; however, some its part remains in the slag, thus leading to metal losses. In order to reduce platinum losses, the forms of platinum in these phases should be studied. The analysis of possible chemical reactions in ore was carried out using the HSC Chemistry software package. It was experimentally established that platinum in matte is present in the form of intermetallics with $\mathrm{Fe}$ and $\mathrm{Ni}$. The Pt-Fe intermetallide is a dispersed needle formation with a length of 20 to $500 \mu \mathrm{m}$ and a thickness of up to $10 \mu \mathrm{m}$. The size effect is revealed: the content of impurities in the PtFe intermetallide increases with decreasing the thickness of needle formations. It was found that matte drops together with the associated $\mathrm{Pt}$, Fe, and $\mathrm{Ni}$ intermetallide particles of no more than 5-7 $\mu \mathrm{m}$ in size, were carried into the slag by gas bubbles, which appear due to decomposition of sulphides. The conditions for the rise of a matte drop, together with a bubble in the slag, consist in the fact that the adhesive force of the drop with the bubble and the buoyancy force acting on the bubble must be greater than the gravity of the drop.
\end{abstract}

Keywords: Platinum, intermetallide, matte, surface tension, flotation

\section{INTRODUCTION}

The world's main reserves of platinum are found in layered intrusions of ultrabasic rocks and sulphide coppernickel ores [1]. Extraction of platinum from sulphide copper-nickel ores is a multi-stage process that involves melting of a previously prepared concentrate in electric ore smelting furnaces, where the melt is divided into sulphide and oxide components (matte and slag). Platinum is generally concentrated in matte; however, some its part remains in the slag, thus leading to metal losses [2,3]. In order to develop technologies providing reduced platinum losses, the mechanism of transition of platinum into slag and the forms of platinum during all the respective stages should be studied. One of the possible options for this transition is the flotation of matte drops containing platinum by gas bubbles that appear due to sulphide decomposition. From the perspective of physical chemistry, flotation implies floating of bodies on the surface of a liquid, whose densities are higher than that of this liquid. During flotation, the bubble must overcome the matte-slag boundary and hold a matte drop when floating in the slag. Thus far, researchers have mainly focused either on the mineralogy of platinum in mature slag disposal areas formed during copper and nickel production [4] or the distribution of platinum between slag and matte [2]. Drops flotation [5] has attracted little attention. The behavior of a gas bubble breaking the surface of two liquids was considered in [6].

Therefore, the aim of the present study was to experimentally study platinum forms in the products of ore melting (matte and slag), to analyze possible chemical reactions in such ores using the HSC Chemistry 9.0 
software package and the flotation conditions of matte drops by slag gas bubbles. The results can be used in studies aimed at increasing the degree of platinum recovery.

\section{MATERIAL AND METHODOLOGY}

Copper-nickel sulphide ore widely used for extracting copper, nickel and platinoids was selected as material for the study. It consists of our data from (wt\%): pyrrhotite 42.8, chalcopyrite 20.0, pentlandite 11.3, magnetite 16.0 and silicates 9.9 and contains $1.1 \mathrm{~g} / \mathrm{t} \mathrm{Pt}$ in the form of predominantly PtAs2. The mineral composition of the ore was determined by $\mathrm{x}$-ray phase analysis. The platinum metal content was determined using an SPECTROFLAME MODULA S inductively coupled plasma atomic emission spectrometer and an ELAN 9000 inductively coupled plasma quadrupole mass spectrometer.

Ore samples were melted in corundum crucibles in a resistor furnace with a graphite heater at a temperature of 1200 and $1300{ }^{\circ} \mathrm{C}$ in the atmosphere of carbon combustion products. The exposure period was 1 hour, and the furnace cooling period was 1 hour. The as-obtained ingots were divided into matte and slag. Polished sections (10 pieces) were made from the samples to study the mineral composition using an Axio Image optical microscope and a Tescan Vega 3 scanning electron microscope equipped with an Oxford Instruments X-act energy dispersion attachment. The electron beam diameter was 2-3 $\mu \mathrm{m}$, which allowed the chemical composition to be determined in micron-sized phases. The content of elements was determined with an accuracy of 0.01-0.02 wt\%. To facilitate the search for platinum-containing phases using microscopes, in some cases, Pt was added to the studied ore in the form of a specially prepared platinum sponge with a particle size not exceeding $100 \mu \mathrm{m}$, in an amount from 1.0 to $2.5 \mathrm{~kg} / \mathrm{t}$. The added platinum interacted with the ore components during heating, soaking at high temperatures and cooling similarly to natural platinum.

\section{RESULTS}

After melting copper-nickel sulphide ore with a natural platinum content $(1.5 \mathrm{~g} / \mathrm{t})$ at a temperature of $1300^{\circ} \mathrm{C}$ and soaking for 15 minutes, skeletal FeNi crystals were found in the sulphide part (matte), which contained single drop-shaped platinum-containing intermetallic particles of no more than $0.5 \mu \mathrm{m}$. Matte, according to the results of X-ray phase analysis, consists of (wt\%) troilite 72.4, bornite 10.1, FeNi alloy 7.0 and magnetite 4.9. Iron in the metal form as a separate phase was not detected.

The addition of platinum metal to the furnace mixture revealed several phases containing Pt. Pt in matte after cooling from $1300^{\circ} \mathrm{C}$ is in the form of intermetallides and probably chemical compounds with $\mathrm{Fe}$ and $\mathrm{Ni}$, which are needle formations from 20 to $500 \mu \mathrm{m}$ long and up to $10 \mu \mathrm{m}$ thick (at $1300^{\circ} \mathrm{C}$ ), Figure 1 . These formations are aggregates of prismatic crystals, which, as shown by chemical analysis using an energy-dispersive attachment, are PtFe intermetallide. The crystals are in a double shell: of $(\mathrm{Pt}, \mathrm{Fe}, \mathrm{Ni})$ intermetallide with a thickness of no more than $1 \mu \mathrm{m}$ and a Pt content in the range of 33.55 to $56.55 \mathrm{wt} \%$., which in turn is bordered by a FeNi alloy. The latter is also found separately from Pt compounds in the form of skeletal crystals. After cooling from $1200^{\circ} \mathrm{C}, \mathrm{PtFe}$ intermetallide crystals have a skeletal shape, smaller size (average thickness of 2-3 $\mu \mathrm{m}$ ), and contain lower amounts of $\mathrm{Pt}$ (from 47 to $63 \mathrm{wt} \%$ ) compared to samples after cooling from $1300^{\circ} \mathrm{C}$.

PtFe intermetallide contains $\mathrm{Cu}$ and $\mathrm{Ni}$ impurities (Ni: 1.86-5.06 wt\%; Cu: 0.79-2.64 wt\%). Such impurities are characteristic of this alloy [7]. The impurity content increases, as in the case of dispersed Au particles, which was established earlier [8], with a decrease in the thickness of the PtFe formations. The ( $\mathrm{Pt}, \mathrm{Fe}, \mathrm{Ni})$ intermetallide features $\mathrm{Cu}(1.97-2.56 \mathrm{wt} \%)$ and $\mathrm{Co}(0.27-0.69 \mathrm{wt} \%)$ impurities. The increase in the impurity content in dispersed needle platinum formations (thickness no more than $10 \mu \mathrm{m}$ ) with a decrease in their thickness $L$ can be explained by an increase in the thermodynamic activity of the dispersed substance.

In order to predict changes in the chemical and phase composition, the authors analyzed possible chemical reactions in the ore, the mineral composition of which is given above, using the Equilibrium Compositions 
module of the HSC Chemistry 9.0 software package for changing the thermodynamic parameters and carbon content. It was found that platinum during heating the ore mass in the range of $0-1300{ }^{\circ} \mathrm{C}$ could be in the following form: platinum, as well as $\mathrm{PtS}, \mathrm{PtFe}, \mathrm{PtFe}_{3}, \mathrm{PtNi}$. Dynamic changes in sulphide ore start in the temperature range of $300-600{ }^{\circ} \mathrm{C}$ : the contents of $\mathrm{C}, \mathrm{Fe}_{7} \mathrm{~S}_{8}, \mathrm{CuFeS}_{2}, \mathrm{Fe}_{3} \mathrm{O}_{4}$, and PtS fall sharply, while $\mathrm{CO}$, $\mathrm{CO}_{2}, \mathrm{FeS}$, and intermetallides including those containing $\mathrm{Pt}$ appear in large quantities. The phase composition and number of phases at different temperatures are affected by carbon. For example, when the carbon content is high, $\mathrm{Fe}, \mathrm{Ni}$, and $\mathrm{Cu}$ are actively reduced, and $\mathrm{FeNi}$ is formed. With an increase in the amount of introduced platinum metal from 0.1 to $2.5 \mathrm{~kg} / \mathrm{t}$ in the initial furnace-charge, the number of platinum-containing products as shown in Figure 3 increases proportionally. However, the products remain unchanged. This indicates that the behavior of platinum during ore heating and melting is not affected by its content.

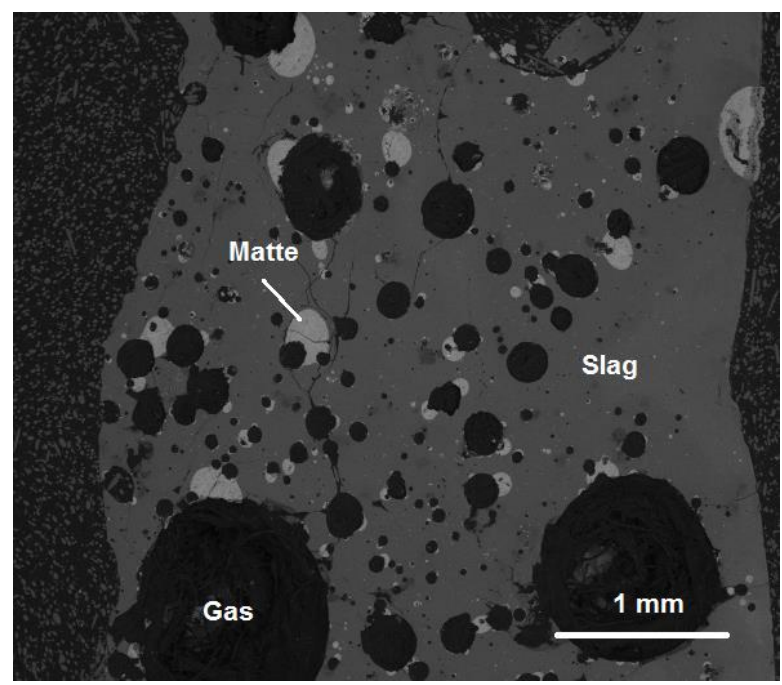

Figure 1 Sulphide drops (Matte) transferred by gas bubbles (Gas) to slag (Slag). Image taken in BSE mode

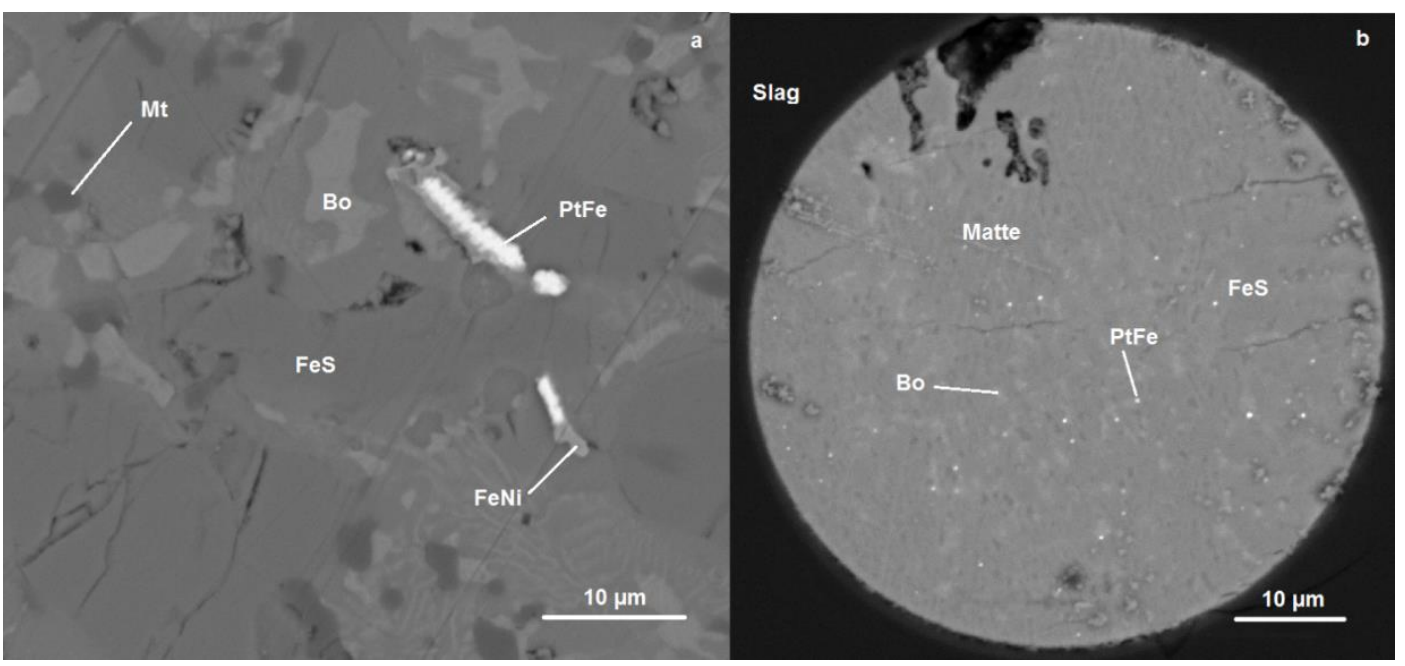

Figure 2 Fragment of a matte drop with Pt particles in slag (a) and a matte drop in slag (b), designations: $\mathrm{PtFe}$ and FeNi - intermetallic compounds and alloys; (FeS) - troilite; Bo - bornite; Mt - magnetite. Image taken in BSE mode

The study of the oxide melt (slag) during the melting of copper-nickel sulphide ore showed the following. The slag is porous due to the release of gas bubbles containing sulphur. These bubbles, as seen from micrographs (Figure 1), float matte drops up to $1.5 \mathrm{~mm}$ in diameter. Irregular-shaped intermetallic particles containing Pt, $\mathrm{Fe}$, and $\mathrm{Ni}$, no more than 5-7 $\mu \mathrm{m}$ in size (Figure 2), and found in the surface layers of slag, are associated 
with these drops. In industrial slags in electric ore smelting furnaces, the platinum content ranges from 0.3 to $1 \mathrm{~g} / \mathrm{t}[4,9]$. Thus, the flotation of matte drops is one of the main processes that lead to losses of valuable metals, including platinum, during the ore-heating melting of $\mathrm{Cu}-\mathrm{Ni}$ sulphide ore on matte.

Table 1 shows the contents of Pt and platinum group metals in the initial ore and melting products obtained by ICP MS. Compounds containing platinoids were not detected by scanning electron microscopy in polished sections, probably because of their low contents. From literature it is known that up to $95 \%$ of palladium in ore is present as impurities in pentlandite $(\mathrm{Ni}, \mathrm{Fe})_{9} \mathrm{~S}_{8}[10]$. The rest of it forms its own minerals paolovite $\mathrm{Pd}_{2} \mathrm{Sn}$, sobolevskite $\mathrm{PdBi}$, stannopalladine $\mathrm{Pd}_{6} \mathrm{Sn}_{3}$ [11]. Other platinoids are found only as impurities in pyrrhotite and pentlandite [10]. The table shows that a significant part of the platinoids goes into slag. This contributes to their losses.

Table 1 The content of precious metals in the melting products of copper-nickel sulphide ore

\begin{tabular}{|c|c|c|c|c|}
\hline Element & Ore $(\mathrm{ppm})$ & Matte $(\mathrm{ppm})$ & Slag $(\mathrm{ppm})$ & Metal fraction in slag (wt\%) \\
\hline $\mathrm{Pt}$ & 1.12 & 1.26 & 0.13 & 11.6 \\
\hline $\mathrm{Pd}$ & 2.52 & 5.36 & 1.51 & 59.9 \\
\hline $\mathrm{Ru}$ & 0.10 & 0.21 & 0.05 & 50.0 \\
\hline $\mathrm{Rh}$ & 0.92 & 2.08 & 0.07 & 7.6 \\
\hline $\mathrm{Ir}$ & 0.01 & 0.01 & traces & unspecified \\
\hline
\end{tabular}
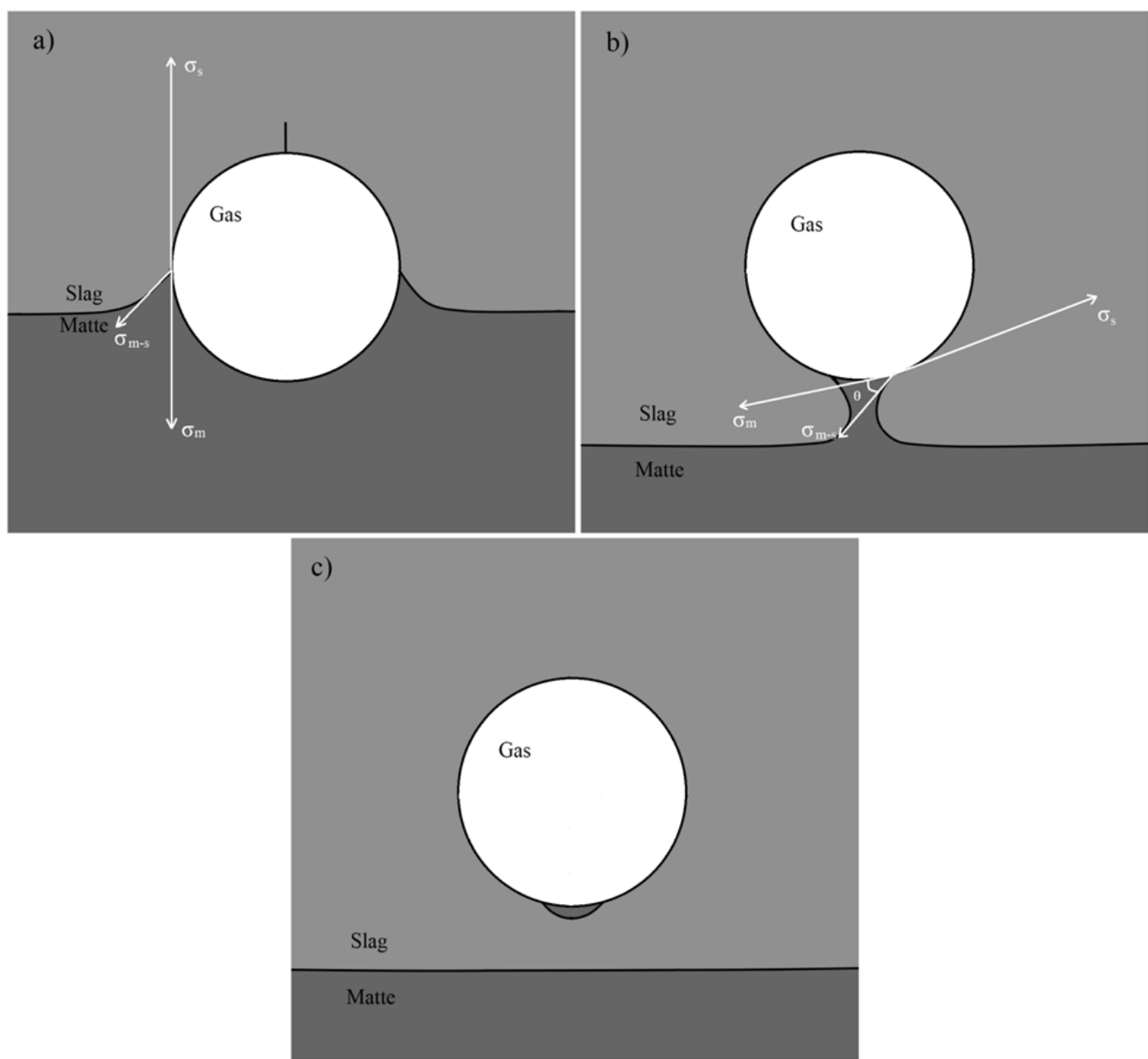

Figure 3 Stages of the passage of the bubble through the matte-slag interface: $a, b-$ transition of the gas bubble through the matte-slag interface; $c$ - floating gas bubble with a matte drop 
The passage of a gas bubble through the boundary of two immiscible liquids is poorly studied. During the passage of this boundary, the bubble can capture and float a drop of heavier liquid. Let us consider the process using the example of the matte-slag boundary and the conditions for the rise of a matte drop with a bubble. Phases close to equilibrium are shown in Figure 3. The analysis was carried out based on photos obtained using a Tescan Vega 3 scanning electron microscope after cooling the matte-slag melt from a temperature of $1300{ }^{\circ} \mathrm{C}$ of sulphide Pt-containing materials.

In order for the bubble to "tear" a matte drop from the sulphide melt and float with it in the slag, two conditions must be met.

1) The drops are held on the bubbles by surface tension, which can be called the coupling force. In order for the drop not to separate from the bubble, the adhesion force of the matte drop to the bubble must be greater than its gravity.

2) The buoyancy force applied to the bubble must be greater than the gravity of the drop. Otherwise, the bubble with the drop will sink.

For the experimentally studied slag and matte, the maximum possible radius of the matte drop $r$ held by the adhesive force on the surface of the gas bubble is about $4 \mathrm{~mm}$.

The ratio of the radius of the matte drop $r$ to the radius of the gas bubble $R$ carrying it, calculated according to the second condition, will be $R \geq 0.7-0.9 \mathrm{r}$.

The size of the bubble raising a matte drop can be even smaller than its size, which is confirmed experimentally.

Matte drops in the slag are involved in the coagulation process. The larger drops already formed in the slag will sink under the action of gravity when it exceeds the resultant interfacial tension. To fulfill this condition, the radius of the matte drops must be greater than $4 \mathrm{~mm}$. Such droplets reach the matte-slag boundary. To merge with matte, drops must overcome interfacial tension. This is done for matte droplets having a radius $r$ greater than $3.8 \mathrm{~mm}$.

Thus, the conditions for the flotation of matte drops are considered.

\section{CONCLUSION}

The mineral composition of Cu-Ni matte sulphide ore, which is widely used for extracting copper, nickel and platinoids, has been studied. It was found that during the heating and melting of this ore in reducing atmospheres, iron, nickel, and copper are reduced. Platinum in matte is present in the form of intermetallides with $\mathrm{Fe}$ and $\mathrm{Ni}$. The PtFe intermetallide is a dispersed needle formation with a length of 20 to $500 \mu \mathrm{m}$ and a thickness of up to $10 \mu \mathrm{m}$. The size effect is revealed: the content of impurities in the PtFe intermetallide (Cu and $\mathrm{Ni}$ ) increases with decreasing the thickness of needle formations. It was found that matte drops, together with the associated $\mathrm{Pt}, \mathrm{Fe}$, and $\mathrm{Ni}$ intermetallide particles of no more than 5-7 $\mu \mathrm{m}$ in size, were carried into the slag by gas bubbles using flotation. This leads to the loss of valuable components, in particular, platinum. The conditions for the rise of a matte drop, together with a bubble in the slag, consist in the fact that the adhesive force of the drop with the bubble and the buoyancy force acting on the bubble must be greater than the gravity of the drop.

\section{ACKNOWLEDGEMENTS}

This work was supported by the RFBR grants No. 18-29-24081|19 and No. 19-38-90080|19. 


\section{REFERENCES}

[1] BELLEMANS, I., DE WILDE, E., MOELANS, N., VERBEKEN, K. Metal losses in pyrometallurgical operations - A review. Adv Colloid Interface Sci. 2018, no. 255, pp. 47-63.

[2] AVARMAA, K., JOHTO, H., TASKINEN, P. Distribution of Precious Metals (Ag, Au, Pd, Pt, and Rh) Between Copper Matte and Iron Silicate Slag. Metallurgical and Materials Transactions B. 2016., vol. 47, no. 1, pp. 244255.

[3] VANYUKOV, A.V., ZAITSEV, V.Ya. Slags and mattes of non-ferrous metallurgy. Moscow: Metallurgy, 1969.

[4] MAKAROV, V.A., MIKHEEV, V.G., SAMORODSKY, P.N. Mineralogy of slag dumps of the Norilsk Nickel Plant. Mountain Journal. 2016, no. 3, pp. 50-55.

[5] MUNGALL, J.E., BRENAN, J.M., GODEL, B., BARNES, S.J., GAILLARD, F. Transport of metals and sulphur in magmas by flotation of sulphide melt on vapour bubbles. Nature Geoscience. 2015, vol. 8, no. 3, pp. 216-219.

[6] GEGUZIN, Y.E. Bubbles. Moscow: Nauka, 1985.

[7] CABRI, L.J., FEATHER, C.E. Platinum-iron alloys: a nomenclature based on a study of natural and synthetic alloys. Can. Mineral. 1975, vol. 13, no. 2, pp. 117-126.

[8] VATOLIN, N.A., AMDUR, A.M., PAVLOV, V.V., FEDOROV, S.A., MATUSHKINA, A.N. Content of impurities in dispersed ore gold particles depending on their size. Doklady Physical Chemistry. 2016, vol. 470, no. 2, pp. 162164.

[9] PETROV, G.V., BAUDOUIN, A.Ya., MARDAR, I.I., IVANOV, B.S., BOGINSKAYA, A.S. Resources of noble metals in technogenic objects of the mining and metallurgical complex of Russia. Advances in modern natural sciences. 2013, no. 3, pp. 145-148.

[10] BORTNIKOV, N.S., DISTLER, V.V., VIKENTYEV, I.V., GAMYANIN, G.N., GRIGORYEVA, A.V., GROKHOVSKAYA, T.L., SERMENIKIN, S.F., TAGIROV, B.R. Forms of finding noble metals in ores of complex deposits: study methodology, quantitative characteristics, technological value. Problems of Minerageny of Russia. Moscow: RAS, Department of Earth Sciences., 2012.

[11] SMIRNOV, V.I. Ore deposits of the USSR. Moscow: Nedra, Volume 3. 1978. 